\title{
Het effect van partiële gebitsprothesen op de levenskwaliteit bij mensen met verkorte tandbogen
}

Om de toegevoegde waarde van partiële gebitsprothesen bij verkorte tandbogen op de levenskwaliteit te onderzoeken, werden bezoekers van 2 universiteitsklinieken gescreend op de aanwezigheid van verkorte of complete tandbogen. De geselecteerden werden ingedeeld in 5 groepen: 1 . een verkorte tandboog en een intact front; 2 . een verkorte tandboog met een frontonderbreking; 3. een verkorte tandboog en een intact front met een vrij-eindigende partiële gebitsprothese; 4 . een verkorte tandboog met meerdere onderbrekingen en een partiële gebitsprothese; 5 . een complete tandboog. De deelnemers vulden de Oral Health Impact Profile (OHIP-49) en de Short Form Health Survey (SF-36) in. Klinisch werd vastgelegd of en welke gebitselementen ontbraken, of deze waren vervangen door een partiële gebitsprothese en hoe groot het aantal occlusale eenheden was. Een verkorte tandboog bleek een zekere impact op de levenskwaliteit te hebben. Van deze invloed bleek echter alleen sprake als de gebitsprothese ook frontelementen verving.

Armellini DB, Heydecke G, Witter DJ, Creugers NHJ. Het effect van partiële gebitsprothesen op de levenskwaliteit bij mensen met verkorte tandbogen Ned Tijdschr Tandheelkd 2009; 116: 687-693

\section{Inleiding}

Dentities waarin 1 of meer gebitselementen ontbreken, kunnen uitsluitend symptomatisch worden behandeld door de afwezige gebitselementen te vervangen. Dat kan met bruggen, implantaten of partiële gebitsprothesen. Vooral als een relatief groot aantal gebitselementen ontbreekt, zijn implantaten en bruggen in veel gevallen onmogelijk of te kostbaar. Partiële gebitsprothesen zijn relatief goedkoop, maar hebben 2 belangrijke nadelen. Het eerste is dat een toegevoegde waarde van een partiële gebitsprothese aan de gebitsfuncties, ook als die objectief aanwijsbaar is, vaak niet als zodanig wordt gewaardeerd (Witter et al, 1990). Het tweede nadeel is dat partiële gebitsprothesen een potentieel negatief effect hebben op de aanwezige gebitselementen. Er moet dus om die redenen veel aandacht worden besteed aan het ontwerp van een partiële gebitsprothese zodat plaqueretentie en trauma van de weefsels wordt voorkomen of beperkt (Petridis en Hempton, 2001; Hummel et al, 2002). Een grondige verzorging van de mond en de gebitsprothese is daarom een vereiste (Öwall et al, 2002). In het algemeen wordt dan ook gesteld dat verkorte tandbogen waarin (bijna) alle premolaren aanwezig zijn, beter niet kunnen worden verlengd met een partiële gebitsprothese (Witter et al, 1999; Wöstmann et al, 2005). Toch blijft het belangrijk de vraag te beantwoorden in welke situaties een partiële gebitsprothese vanuit functionele, psychische en sociale behoeften nuttig kan zijn. Tevens is het nuttig deze behoeften te kwantificeren. Dit kan voorkómen dat partiële gebitsprothesen worden vervaardigd die niet worden gedragen omdat patiënten er geen profijt van hebben of ze als hinderlijk ervaren.

Om de invloed van de orale condities op de beleving van de levenskwaliteit te kwantificeren, worden onder andere een specifiek instrument, de Oral Health Impact Profile (OHIP-49), en een algemeen instrument, de Short Form Health Survey (SF-36), gebruikt (Ware en Sherbourne 1992; Slade en Spencer, 1994; Allen et al, 1999; Akifusa et al, 2005; Ware, 2007). Dit zijn vragenlijsten die bijvoorbeeld worden gebruikt om de uitkomst te bepalen van behandelingen met volledige en partiële gebitsprothesen (Heydecke et al, 2003; John et al, 2004). Zo werden in een pilotonderzoek 2 groepen patiënten die een verschillende behandeling van hun gemutileerde verkorte tandbogen hadden ondergaan, met elkaar vergeleken (Wolfart et al, 2005). Een groep met bruggen om een premolarendentitie te herstellen versus een groep patiënten bij wie de verkorte tandbogen niet alleen werden hersteld, maar ook werden verlengd met een partiele gebitsprothese. Er werden, in termen van impact op de levenskwaliteit, geen significante verschillen gevonden tussen deze 2 behandelstrategieën. Andere onderzoekers beschreven 3 verschillende behandelstrategieën bij eenzijdig verkorte tandbogen: 1 . verlenging met een implantaatbrug; 2. verlenging met een conventionele partiële gebitsprothese of 3. geen verlenging van de tandboog. Een enquête gericht op het niveau van levenskwaliteit gaf wel een hogere score voor de eerste groep, maar de niveaus van levenskwaliteit tussen de tweede en de derde groep verschilden niet significant (Kuboki et al, 1999).

Het doel van het voorliggende cross-sectionele onderzoek was de impact van verkorte tandbogen, al dan niet onder-

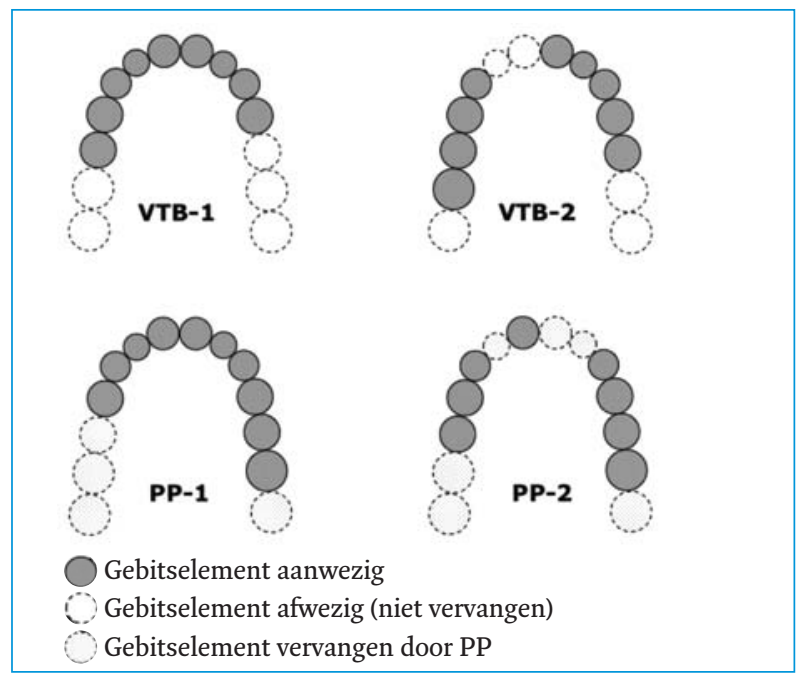

Afb. 1. Voorbeelden van verkorte tandbogen in termen van aanwezige, afwezige en door partiële gebitsprothesen vervangen gebitselementen in de onderzochte groepen. 


\begin{tabular}{|c|c|c|c|c|c|}
\hline Variabele & VTB-1 & VTB-2 & PP-1 & PP-2 & СТВ \\
\hline $\begin{array}{l}\text { Aantal personen } \\
\text { Gemiddelde leeftijd (sd) } \\
\text { Percentage vrouwen } \\
\text { Gemiddeld aantal gebits- } \\
\text { elementen (sd) } \\
\text { - BK } \\
\text { - OK } \\
\text { Aantal (en \%) personen met } \\
\text { afwezige gebitselementen } \\
\text { - alleen BK } \\
\text { - alleen OK } \\
\text { - BK + OK } \\
\text { Aantal (en \%) personen met } \\
\text { frontonderbrekingen } \\
\text { - alleen BK } \\
\text { - alleen OK } \\
\text { - BK + OK } \\
\text { Gemiddeld aantal (sd) afwezige } \\
\text { frontelementen } \\
\text { - alleen BK } \\
\text { - alleen OK } \\
\text { - BK + OK: BK } \\
\text { - BK + OK: OK }\end{array}$ & $\begin{array}{c}11,1(1,7) \\
10,7(2,2) \\
5(11) \\
3(7) \\
36(82)\end{array}$ & $\begin{array}{l}7,8(2,3) \\
9,0(2,2) \\
0 \\
0 \\
21(100) \\
15(70) \\
3(15) \\
3(15) \\
\\
2,6(1,2) \\
2,0(1,7) \\
3,7(0,6) \\
2,0(1,7)\end{array}$ & $\begin{array}{c}9,2(2,9) \\
9,0(2,3) \\
9(36) \\
6(24) \\
10(40)\end{array}$ & $\begin{array}{c}7,8(3,5) \\
9,3(2,4) \\
\\
14(44) \\
4(12) \\
14(44) \\
\\
18(56) \\
6(19) \\
8(25) \\
\\
2,9(1,5) \\
2,2(1,2) \\
2,8(1,5) \\
3,0(1,2)\end{array}$ & $\begin{array}{l}38 \\
32(10) \\
47\end{array}$ \\
\hline
\end{tabular}

Tabel 1. Aantal personen, leeftijd, geslacht en tandboogkarakteristieken in de groepen VTB-1, VTB-2, PP-1, PP-2 en CTB (sd = standaarddeviatie; BK= bovenkaak; OK = onderkaak).

broken in het front, en de toegevoegde waarde van partiële gebitsprothesen op de levenskwaliteit te kwantificeren met behulp van de OHIP-49 en de SF-36. De uitkomsten werden vergeleken met die van personen met complete tandbogen als controlegroep. De nulhypothese daarbij was dat er geen verschillen zijn in de levenskwaliteit tussen personen met verkorte tandbogen, personen met verkorte tandbogen verlengd met partiële gebitsprothesen en personen met complete tandbogen. Bijgevolg was er ook nog de nulhypothese dat een vrij-eindigende partiële gebitsprothese geen toegevoegde waarde biedt bij personen met verkorte tandbogen.

\section{Materiaal en methode}

Een niet-gerandomiseerd cross-sectioneel onderzoek werd uitgevoerd in 2 universiteitsklinieken in de Verenigde Staten. Personen die zich wilden laten inschrijven en potentieel geschikt waren voor dit onderzoek, werden gevraagd aan het onderzoek mee te werken. Alle deelnemers hadden voldoende lees- en schrijfvaardigheid om een vragenlijst in te vullen. Aan de eisen van de 'Declaration of Helsinki' (1989) en de lokale ethische commissies was voldaan en de participanten tekenden een 'informed consent'. De geselecteerden, ouder dan 18 jaar, werden naar gebitssituatie in 5 groepen ingedeeld: een verkorte tandboog met een intact front (VTB1 ), een verkorte tandboog en een tandboogonderbreking in het front (VTB-2), een verkorte tandboog met intact front waarbij de tandboog was verlengd met een vrij-eindigende partiële gebitsprothese (PP-1), onderbrekingen in de ver- korte tandboog in de zijdelingse delen en in het front met een partiële gebitsprothese ter vervanging van gebitselementen in de zijdelingse delen en in het front (PP-2), en een complete tandboog (CTB) (afb. 1).

Een kort klinisch onderzoek werd uitgevoerd door 1 van 2 gekalibreerde tandartsen (de eerste 2 auteurs). Aan de deelnemers werd gevraagd een OHIP-49 en een SF-36vragenlijst in te vullen. Van de 196 deelnemers konden van 160, 82 mannen en 78 vrouwen, alle benodigde gegevens worden verzameld (tab. 1). Personen met incomplete gegevens werden uitgesloten. Bij het klinische onderzoek werden alle aanwezige gebitselementen geregistreerd en van de afwezige gebitselementen de prothetische vervanging door middel van een partiële gebitsprothese. Tevens werd het aantal occlusale eenheden geregistreerd. Uit het gemiddelde aantal aanwezige gebitselementen bleek dat verkorte tandbogen (met afwezigheid van molaarocclusie) en extreem verkorte tandbogen (met afwezigheid van molaar- en premolaarocclusie) aanwezig waren (tab. 1). De OHIP-49 en de SF-36 bevatten items die betrekking hebben op verschillende domeinen (tab. 2). De OHIP-49-scores werden uitgedrukt in de 5-punten Likertschaal: $0=$ nooit tot $4=$ heel vaak. De SF-36-vragen werden gescoord in 2- tot 6-puntenschalen. De algoritmen die zijn vermeld in de instructies van de SF-36 over de domeinen werden toegepast (Ware en Sherbourne, 1992; Ware, 2007).

Allereerst werden de validiteit en de betrouwbaarheid van de domeinen van de OHIP-49 en de SF-36 onderzocht 


\begin{tabular}{|l|l|} 
OHIP-49 & SF-36 \\
Functiebeperking & Lichamelijk functioneren \\
$\quad$ kauwen, spreken, esthetiek & activiteiten als baden en aankleden \\
Pijn & Rolvervulling fysiek \\
kiespijn, pijnlijke kaken & problemen met werk \\
Psychisch ongemak & Pijn \\
zorgen maken, ongemakkelijk voelen & incidentie, intensiteit \\
Lichamelijke beperking & Algemene gezondheid \\
lachen vermijden, onduidelijk spreken & achteruitgang, incidentie van ziekte \\
Psychische beperking & Vitaliteit \\
van streek zijn, gegeneerd voelen & energie hebben, vermoeid voelen \\
Sociale belemmering & Sociaal functioneren \\
niet de deur uitgaan, prikkelbaar zijn & contacten vermijden \\
Handicap & Rolvervulling emotioneel \\
niet kunnen genieten/functioneren & interferentie met werk of andere activiteiten \\
Psychische gezondheid & \\
nerveus/ongelukkig voelen & \\
\hline
\end{tabular}

Tabel 2. Voorbeelden van items in de diverse domeinen van de OHIP-49 en de SF-36.

door middel van factoranalyse en Cronbach's alfa. Vervolgens werd nagegaan of leeftijd invloed had op de uitkomsten. Als dit zo was, werden de uitkomsten gecorrigeerd naar 60-jarige leeftijd. Correctie voor geslacht werd als standaardprocedure toegepast voor alle domeinen. Lineaire regressiemodellen werden gebruikt om de groepen te vergelijken. Poweranalyses werden uitgevoerd voor groepsvergelijkingen die relevant waren om de hypothesen te testen, namelijk VTB-1 versus CTB, VTB-2 versus CTB, VTB-1 versus PP-1, VTB-2 versus PP-2 en VTB-1 versus VTB-2. Ten slotte werd in de groep VTB-1 het effect van het aantal en de lokalisering (één- versus tweezijdig) van de occlusale eenheden op de scores van de OHIP-49- en SF-36 geanalyseerd met behulp van een regressiemodel waarin ook geslacht en leeftijd waren opgenomen.

\section{Resultaten}

Uit de factoranalysen bleek dat de scores op de items van de OHIP-49 en de SF-36 consistent waren met de scores op de afzonderlijke domeinen, hetgeen betekent dat de vragen valide zijn voor de onderzochte populatie. Cronbach's alfa varieerde van 0,82 tot 0,97 voor de OHIP-49-domeinen, en van 0,80 tot 0,94 voor de SF-36-domeinen. Dit onderstreept de betrouwbaarheid van beide vragenlijsten.

Leeftijdseffecten werden gevonden voor een aantal van de onderzoeksgroepen, zowel voor de OHIP-49 als voor de SF-36 (tab. 3 en 4). De gemiddelden van deze groepen werden voor deze effecten in de desbetreffende domeinen gecorrigeerd. De gevonden effecten waren voor beide vragenlijsten negatief, dus ouderen hadden lagere gemiddelde scores en dit betekent dat zij minder klachten hadden, maar wel een slechtere gezondheid. Een significant positief geslachtseffect was er voor de OHIP-49-domeinen 'functiebeperking', 'pijn', en 'psychisch ongemak', dat wil zeggen dat vrouwen meer klachten hadden. Op de SF-36 scoorden vrouwen significant negatiever in de domeinen 'algemene gezondheid' en 'vitaliteit'. Dit duidt op een als slechter ervaren gezondheid.

\section{OHIP-49}

Alle experimentele groepen hadden significant hogere scores (meer klachten) dan de controlegroep op de domeinen 'functiebeperking', 'psychisch ongemak', en 'lichamelijke beperking' van de OHIP-49 (tab. 3). De groepen VTB-2, PP-1 en PP-2 hadden bovendien significant hogere scores op het domein 'pijn' dan de groep CTB. De groepen VTB2 en PP-2 hadden eveneens hogere scores op het domein 'psychische beperking' dan de groep CTB.

Binnen de 4 experimentele groepen had de groep VTB-1 in het algemeen de laagste scores (minste klachten). Voor alle domeinen met uitzondering van 'psychisch ongemak' scoorde de groep VTB-1 significant lager (minder klachten) dan de groep VTB-2. De uitkomsten van de groep PP-1 verschilden niet significant van de groep VTB-1, met uitzondering van een significant hogere score voor 'pijn'. De relatief grote standaarddeviaties in het domein 'pijn' in de groepen VTB-2 en PP-1 wijzen op een grote individuele variatie. De groep VTB-2 had op alle domeinen de hoogste gemiddelde scores. Op de domeinen 'functiebeperking' en 'pijn' had de groep PP-2 significant lagere scores (minder klachten) dan de groep VTB-2.

Uit een post-hoc poweranalyse bleek de kans om tussen de groepen significante verschillen te vinden in de uitkomsten van de domeinen van de OHIP-49 in 5 (14\%) van de totaal 35 vergelijkingen ( 5 vergelijkingen van de groepen op 7 domeinen) minder dan $80 \%$ te zijn (tab. 5). Zo is bijvoorbeeld de power van de vergelijking tussen de groepen VTB-1 en PP-1 voor het domein 'pijn' onvoldoende $(0,68)$.

\section{$S F-36$}

In het algemeen waren de verschillen tussen de experimentele groepen en de controlegroep in de SF-36 minder 


\begin{tabular}{|c|c|c|c|c|c|c|}
\hline Domein & VTB-1 & VTB-2 & PP-1 & PP-2 & СТВ & $\mathrm{p}$ \\
\hline Functiebeperking\# & $1,2(0,2)^{15}$ & $1,9(0,2)^{256}$ & $1,5(0,3)^{3}$ & $1,4(0,2) * 46$ & $0,6(0,1)^{1234}$ & $<, 01$ \\
\hline Pijn\# & $0,9(0,3)^{45}$ & $1,5(0,9) * 146$ & $1,4(0,8)^{25}$ & $1,0(0,4)^{36}$ & $0,6(0,1)^{123}$ & $<, 05$ \\
\hline Psychisch ongemak & $1,4(0,2)^{1}$ & $1,7(0,3) * 2$ & $1,7(0,4)^{3}$ & $1,7(0,3) * 4$ & $0,7(0,2)^{1234}$ & $<, 05$ \\
\hline Lichamelijke beperking & $0,5(0,2)^{156}$ & $1,3(0,2) * 25$ & $1,0(0,3)^{3}$ & $1,1(0,2) * 46$ & $0,2(0,1)^{1234}$ & $<, 05$ \\
\hline Psychische beperking\# & $0,6(0,2)^{3}$ & $1,2(0,2)^{* 13}$ & $0,8(0,3)$ & $0,9(0,2) * 2$ & $0,3(0,1)^{12}$ & $<, 001$ \\
\hline Sociale belemmering & $0,3(0,3)^{1}$ & $0,7(0,3)^{* 1}$ & $0,3(0,3)$ & $0,5(0,3)^{*}$ & $0,2(0,3)$ & $<, 01$ \\
\hline Handicap & $0,4(0,3)^{1}$ & $0,8(0,3)^{* 1}$ & $0,8(0,4)$ & $0,4(0,3)$ & $0,5(0,3)$ & $<, 05$ \\
\hline
\end{tabular}

Tabel 3. Gemiddelde scores en standaarddeviaties in de groepen VTB-1, VTB-2, PP-1, PP-2 en CTB voor elk OHIP-49-domein na leeftijdcorrectie (60 jaar). De scores variëren van 0 tot 4. Een hogere score betekent meer klachten (\# = significant geslachtsverschil; * = significant negatief leeftijdseffect: ouderen rapporteerden minder klachten; gelijke cijfers ${ }^{1} \mathrm{t} / \mathrm{m}^{6}=$ significant verschil).

\begin{tabular}{|c|c|c|c|c|c|c|}
\hline Domein & VTB-1 & VTB-2 & PP-1 & PP-2 & СТВ & $\mathrm{p}$ \\
\hline Lichamelijk functioneren & $79,8(5,4)^{* 1}$ & $75,0(6,7)^{2}$ & $79,0(8,7)$ & $85,9(5,7)$ & $92,3(4,3)^{12}$ & $<, 05$ \\
\hline Rolvervulling fysiek & $79,0(18,5)^{1}$ & $71,1(19,4)$ & $74,5(19,1)$ & $82,3(18,7)^{2}$ & $38,5(18,0)^{* 12}$ & $<, 05$ \\
\hline Pijn & $73,0(5,5)$ & $66,3(6,7)^{1}$ & $66,2(6,4)^{2}$ & $79,2(5,9)$ & $81,6(4,4)^{12}$ & $<, 05$ \\
\hline Algemene gezondheid\# & $76,3(3,7)$ & $71,7(4,6)$ & $73,1(4,3)$ & $77,7(3,9)$ & $71,8(2,9)$ & - \\
\hline Vitaliteit\# & $65,5(4,2)$ & $59,3(5,7)^{1}$ & $67,7(5,3)$ & $71,8(4,9)^{1}$ & $67,5(3,7)$ & $<, 05$ \\
\hline Sociaal functioneren & $73,3(9,7)$ & $68,4(10,2)^{1}$ & $70,6(10,0)$ & $79,5(9,9)^{1}$ & $63,1(9,4)^{*}$ & $<, 05$ \\
\hline Rolvervulling emotioneel & $80,2(18,1)$ & $65,9(19,1)$ & $81,9(18,7)$ & $86,3(18,1)$ & $53,4(17,6)^{*}$ & - \\
\hline Psychische gezondheid & $81,6(4,0)^{1}$ & $72,0(4,3)^{12}$ & $79,5(4,0)$ & $84,0(3,7)^{2}$ & $77,6(2,8)$ & $<, 05$ \\
\hline
\end{tabular}

Tabel 4. Gemiddelde scores en standaarddeviaties in de groepen VTB-1, VTB-2, PP-1, PP-2 en CTB voor elk SF-36-domein na leeftijdcorrectie (60 jaar). De scores variëren van 0 tot 100. Een hogere score betekent betere gezondheid en voor het domein 'pijn' betekent dit minder pijn. (\# = significant ge-

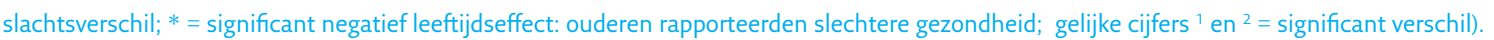

markant en minder overtuigend dan in de OHIP-49 (tab. 4). Alleen voor de domeinen 'lichamelijk functioneren', 'rolvervulling fysiek' en 'pijn' scoorden sommige experimentele groepen significant verschillend van de controlegroep. Deze verschillen lieten echter niet eenduidig een betere gezondheid zien voor de laatste groep, want 2 domeinen scoorden lager en 1 hoger dan in de controlegroep.

Van alle groepen had de groep VTB-2 de laagste scores (slechtste gezondheid). De groep PP-2 had significant hogere gemiddelde scores dan de groep VTB-2 op de domeinen 'vitaliteit', 'sociaal functioneren' en 'psychische gezondheid'. Hier is dus een positief effect van de partiële gebitsprothese aanwijsbaar.

Uit een post-hoc poweranalyse bleek de kans om tussen de groepen significante verschillen te vinden in de uitkomsten van de domeinen van de SF-36 in 10 van de in totaal 40 vergelijkingen ( 5 vergelijkingen van de groepen op 8 domeinen) minder dan $80 \%$ te zijn (tab. 5).Voor de groep VTB-1 was er een significant effect van het aantal occlusale eenheden in 5 van de 7 domeinen van de OHIP-49 en in 2 van de 8 domeinen van de SF-36 (tab. 6). De grootste impact had uiteraard 0 occlusale eenheden. Elke additionele occlusale eenheid deed de desbetreffende score op de OHIP-49 afnemen (minder klachten). Bijvoorbeeld: de gemiddelde score voor het domein 'functiebeperking' van de OHIP-49 was 2,0 bij 0 occlusale eenheden, 1,8 bij 1 occlusale eenheid en 1,2 bij 4 occlusale eenheden. Binnen de OHIP-49-domeinen varieerde de vermindering van de gemiddelde score per additionele occlusale eenheid van 9\% ('lichamelijke beperking') tot $17 \%$ ('psychisch ongemak'). Binnen de SF-36 domeinen waren die effecten minder duidelijk, namelijk van $5 \%$ tot $9 \%$ per additionele occlusale eenheid. Wat dat betreft maakte het geen verschil of het nu eenzijdig ( $n=12$ ) dan wel tweezijdig verkorte tandbogen $(n=32)$ betrof: de $p^{-}$ waarden varieerden van 0,47 tot 0,98 als het effect van een additionele occlusale eenheid bij eenzijdig verkorte tandbogen werd vergeleken met dat bij tweezijdig verkorte tandbogen. De gemiddelde scores op de OHIP-49-domeinen verschilden van $8 \%$ minder klachten tot $4 \%$ meer klachten bij eenzijdig verkorte tandbogen. Van de SF-36-domeinen varieerden de verschillen in gemiddelde scores van $-6 \%$ tot $12 \%$ in de perceptie van algemene gezondheid.

\section{Discussie}

De scheve leeftijdsverdeling heeft wellicht de uitkomsten van dit onderzoek beïnvloed. In de onderzochte conveniënte groepen van de 2 universiteitsklinieken waren ouderen met complete tandbogen minder vertegenwoordigd. In geval van een leeftijdseffect werden de uitkomsten gecorrigeerd voor leeftijd. Opvallend is dat voor de OHIP-49 alleen leeftijdseffecten zijn gevonden in de groepen VTB-2 en PP-2. In beide groepen was het effect negatief, dus ouderen hadden minder klachten. Een leeftijdseffect werd ook gevonden in epidemiologisch onderzoek in Australië en het Verenigd Koninkrijk (Steele et al, 2004). Er kan worden verondersteld dat een zekere adaptatie aan of berusting in de toestand van 


\begin{tabular}{|l|l|c|}
\multicolumn{1}{|c|}{ Domein } & Kans (\%) \\
Vergelijking & & 68 \\
VTIP-49 & Pijn & 63 \\
VTB-2 vs. PP-2 & Psychische beperking & 54 \\
& Pijn & 60 \\
VTB-1 vs. VTB-2 & Sociale belemmering & 72 \\
SF-36 & Pijn & \\
VTB-1 vs. CTB & & 63 \\
VTB-2 vs. CTB & & 69 \\
& Vitaliteit & 54 \\
VTB-1 vs. PP-1 & Sociaal functioneren & 65 \\
& Rolvervulling emotioneel & 73 \\
VTB-2 vs. PP-2 & Algemene gezondheid & 66 \\
VTB-1 vs. VTB-2 & Vitaliteit & 67 \\
& Psychische gezondheid & 61 \\
& Rolvervulling fysiek & 71 \\
\hline
\end{tabular}

Tabel 5. Onderlinge vergelijkingen van de groepen VTB-1, VTB-2, PP-1, PP-2 en CTB met een kans van $80 \%$ of minder om de significantie van een werkelijk aanwezig domeinverschil te ontdekken.

het gebit de klachten doet verminderen. Deze veronderstelling kon in dit onderzoek niet worden geverifieerd omdat er niet was gevraagd hoelang de gebitssituatie aanwezig was. Onduidelijk is waarom in 2 groepen wel een significant leeftijdseffect werd gevonden en in de overige 3 groepen niet.

In de groep CTB kwamen 3 van de 4 gevonden leeftijdseffecten in de SF-36-domeinen voor. Alle effecten waren negatief, dus met toenemende leeftijd werd de gezondheid als minder ervaren. De opmerkelijk lage score op het domein 'rolververvulling fysiek' in de groep CTB is wellicht het gevolg van het feit dat de vragen in dit domein zijn gerelateerd aan werk- en niet aan gezondheidsaspecten. Werkgerelateerde problemen hebben waarschijnlijk een grotere impact voor deze relatief jonge groep dan voor de experimentele groepen waarin de ouderen beter waren vertegenwoordigd.

Met betrekking tot de onderzoekshypothese is een significante impact op levenskwaliteit gevonden voor 3 OHIP49-domeinen, te weten 'functiebeperking', 'psychisch ongemak' en 'lichamelijke beperking'. Deze impact lijkt relatief gering voor verkorte tandbogen die in het front niet onderbroken zijn en is ook afhankelijk van het aantal occlusale eenheden (tab. 3). Hoe meer occlusale eenheden aanwezig zijn, des te geringer is de impact (tab. 6). Voor de kauwfunctie is dat voor de hand liggend: het objectieve kauwvermogen correleert met het aantal occlusale eenheden (Van der Bilt et al, 1993). In een onderzoek onder ouderen met de SF-20 werd een relatie gevonden tussen het aantal occlusale eenheden en het domein 'rolvervulling fysiek', maar niet met de overige domeinen van de SF-20 (Jepson et al, 2003). Het huidige onderzoek laat eveneens een directe impact zien van verkorte tandbogen, niet alleen op functionele, maar ook op psychische en sociale domeinen, al is dit minder duidelijk. Dat betekent dat de impact van het verlies van gebitselementen op de levenskwaliteit complexer is dan uitsluitend functionele parameters kunnen aangeven (Morita et al, 2007).

Een vergelijking van de groepen VTB-1 en PP-1 laat voor een vrij-eindigende partiële gebitsprothese geen toegevoegde waarde zien, terwijl toch voor de meeste domeinen een kans van $80 \%$ bestond dat die toegevoegde waarde zou zijn opgemerkt als die er wel was geweest. Overigens was ook voor de OHIP-49-domeinen met onvoldoende power de impact van een partiële gebitsprothese op de levenskwaliteit groter (tab. 3). Het bevestigt een klinisch onderzoek in het Verenigd Koninkrijk naar tevredenheid, waarin verlenging van verkorte tandbogen met vaste en uitneembare prothetische constructies werd vergeleken (Jepson et al, 2003). In een ander onderzoek zijn gelijke scores gevonden voor levenskwaliteit voor eenzijdig verkorte tandbogen, ongeacht of deze nu wel (met een partiële gebitsprothese) of niet waren verlengd (Kuboki et al, 1999). Ook in het huidige onderzoek werden geen significante verschillen gevonden tussen een- en tweezijdig verkorte tandbogen. Het geringe aantal personen (12 respectievelijk 32) maakte de power echter onvoldoende om mogelijke aanwezige interacties te vinden, bijvoorbeeld interacties met het aantal occlusale eenheden.

De hoogste impact op de levenskwaliteit werd gevonden voor de groep met ontbrekende frontelementen die niet prothetisch waren vervangen (VTB-2). Op het eerste gezicht is het merkwaardig dat er geen verschil werd gevonden voor het domein 'psychisch ongemak' tussen de groepen VTB1 en VTB-2. Men zou kunnen redeneren dat als personen in de groep VTB-2 werkelijk serieuze psychische problemen zouden hebben gehad, ze prothetisch zouden zijn behandeld. Na behandeling met bruggen zouden ze tot de groep VTB-1 hebben behoord of na behandeling met een parti- 


\begin{tabular}{|c|c|c|c|}
\hline Domein & $\begin{array}{l}\text { Gemiddelde score } \\
0 \text { OE (sd) }\end{array}$ & $\partial$ per $\mathrm{OE}(\mathrm{sd})$ & $\mathrm{p}$ \\
\hline \multicolumn{4}{|l|}{ OHIP-49 } \\
\hline Functiebeperking & $2,0 \quad(0,3)$ & $-0,2 \quad(0,1)$ & 0,004 \\
\hline Pijn & $1,6 \quad(0,2)$ & $-0,2 \quad(0,1)$ & 0,001 \\
\hline Psychisch ongemak & $2,5 \quad(0,4)$ & $-0,3 \quad(0,1)$ & 0,003 \\
\hline Lichamelijke beperking & $2,3 \quad(0,2)$ & $-0,2 \quad(0,1)$ & 0,004 \\
\hline Psychische beperking & $1,2 \quad(0,3)$ & $-0,2 \quad(0,1)$ & 0,04 \\
\hline Sociale belemmmering & $0,5 \quad(0,3)$ & $-0,01(0,1)$ & n.s. \\
\hline Handicap & $0,7 \quad(0,2)$ & $-0,01(0,1)$ & n.s. \\
\hline \multicolumn{4}{|l|}{ SF-36 } \\
\hline Lichamelijk functioneren & $67,8 \quad(9,3)$ & $3,8 \quad(2,2)$ & n.s. \\
\hline Rolvervulling fysiek & $66,7(16,1)$ & $2,4 \quad(3,7)$ & n.s. \\
\hline Pijn & $55,6 \quad(8,9)$ & $5,1 \quad(2,1)$ & 0,02 \\
\hline Algemene gezondheid & $63,4 \quad(5,8)$ & $3,6 \quad(1,4)$ & 0,01 \\
\hline Vitaliteit & $61,4 \quad(7,3)$ & $2,9 \quad(1,7)$ & n.s. \\
\hline Sociaal functioneren & $62,8 \quad(8,6)$ & $2,6 \quad(2,0)$ & n.s. \\
\hline Rolvervulling emotioneel & $64,6(14,5)$ & $5,1 \quad(3,4)$ & n.s. \\
\hline Psychische gezondheid & $80,6 \quad(5,8)$ & $0,6 \quad(1,3)$ & n.s. \\
\hline
\end{tabular}

Tabel 6. Gemiddelde scores en standaarddeviaties van de domeinen van de OHIP-49 en de SF-36 voor de groep VTB-1 $(n=44)$ na correctie voor leeftijd (60 jaar), geslacht en aantal occlusale eenheden (OE). De gemiddelde score heeft betrekking op verkorte tandbogen met $0 \mathrm{OE}$. $\partial$ per OE is het geschatte verschil van de gemiddelde score voor elke additionele $\mathrm{OE}$ (n.s. = niet significant)

ele gebitsprothese waarbij niet alleen de afwezige frontelementen worden vervangen, maar ook de tandboog wordt verlengd tot de groep PP-2. Vergelijking van de groepen VTB-2 en PP-2 liet inderdaad toegevoegde waarde zien van een partiële gebitsprothese met betrekking tot de impact op de levenskwaliteit, hoewel die toegevoegde waarde alleen significant was voor de 2 OHIP-49-domeinen 'functiebeperking' en 'pijn', en voor de 3 SF-36-domeinen 'vitaliteit', 'sociaal functioneren' en 'psychische gezondheid'.

Evenals in ander onderzoek is de SF-36 minder gevoelig dan de OHIP-49 als het erom gaat voor de te onderscheiden gebitssituaties verschillen aan te tonen in termen van levenskwaliteit (Allen et al, 1999; Akifusa et al, 2005; Morita et $\mathrm{al}, 2007)$. Dit is ook terug te zien in het relatief grotere aantal vergelijkingen met onvoldoende power bij de SF-36 dan bij de OHIP-49.

In het algemeen kan worden gesteld dat er consensus is dat de OHIP-49 en de SF-36 beide kunnen worden gebruikt voor het vergelijken van groepen (Locker, 2004). Er is ook consensus dat voor een enkel individu deze instrumenten minder geschikt zijn om de impact van de gebitssituatie of van een therapeutische interventie te onderzoeken (Wilson en Cleary, 1995; Locker en Gibson, 2005). De vraag kan worden gesteld in hoeverre de uitkomsten van dit onderzoek onder bezoekers van 2 universiteitsklinieken representatief zijn voor mensen in andere (grote) steden en plattelandsgebieden in de Verenigde Staten. Transculturele verschillen kunnen belangrijke verschillen opleveren in de perceptie van verschillende gebitssituaties. Wat dat betreft verdient het aanbeveling dit onderzoek ook in Nederland uit te voeren.

\section{Conclusie}

Dit onderzoek toonde aan dat vanuit het perspectief levenskwaliteit van een partiële gebitsprothese alleen voordeel werd ervaren als daarmee ook ontbrekende gebitselementen in het front waren vervangen. Dit voordeel kon niet worden aangetoond als een verkorte tandboog met een partiële gebitsprothese alleen maar was verlengd.

\section{Literatuur}

* Akifusa S, Soh I, Antai T, et al.Relationship of number of remaining teeth to health-related quality of life in community-dwelling elderly. Gerodontology 2005; 22: 91-97.

* Allen PF, McMillan AS, Walshaw D, Locker DA comparison of the validity of generic - and disease-specific measures in the assessment of oral health-related quality of life. Community Dent Oral Epidemiol 1999; 27: 344-352.

* Bilt A van der, Olthoff LW, Bosman F, Oosterhaven ST.he effect of missing postcanine teeth on chewing performance in man. Archs Oral Biol 1993; 38: 423-429.

* Heydecke G, Locker D, Awad MA, Lund JP, Feine JBral and general health-related quality of life with conventional and implant dentures. Community Dent Oral Epidemiol 2003; 31: 161-168.

* Hummel SK, Wilson MA, Marker VA, Nunn MEQuality of removable partial dentures worn by the adult U.S. population. J Prosthet Dent 2002; 88: 37-43.

* Jepson N, Allen F, Moynihan P, Kelly P, Thomason Matient satisfaction following restoration of shortened mandibular dental arches in a randomized controlled trial. Int J Prosthodont 2003; 16: 409-414.

* John MT, Slade GD, Szentpétery A, Setz JMOral health-related quality of life in patients treated with fixed, removable, and complete den- 
tures 1 month and 6 to 12 month after treatment. Int J Prosthodont 2004; 17: 503-511.

* Kuboki T, Okamoto S, Suzuki H, et alQuality of life assessment of bone-anchored fixed partial denture patients with unilateral mandibular distal-extension edentulism. J Prosthet Dent 1999; 82: 182-187.

* Locker D.Oral health and quality of life. Oral Health Prev Dent 2004: 2 (Suppl. 1): 247-253.

* Locker D, Gibson BDiscrepancies between self-ratings of and satisfaction with oral health in two older adult populations. Community Dent Oral Epidemiol 2005; 33: 280-288.

* Morita I, Nakagaki H, Kato K, et al. Relationship between number of natural teeth in older Japanese people and health related functioning. J Oral Rehabil 2007; 34: 428-432.

* Öwall B, Budtz-Jörgensen E, Davenport J, et aRemovable partial denture design: a need to focus on hygienic principles? Int J Prosthodont 2002; 15: 371-378.

* Petridis H, Hempton TJPeriodontal considerations in removable partial denture treatment: a review of the literature. Int J Prosthodont 2001; 14: 164-172.

* Slade GD, Spencer AJ.Development and evaluation of the Oral Health Impact Profile. Community Dent Health 1994; 11: 3-11.

* Steele JG, Sanders AE, Slade GD, et alHow do age and tooth loss affect oral health impacts and quality of life? A study comparing two national samples. Community Dent Oral Epidemiol 2004; 32: 107-114.

* Ware JE jr, Sherbourne CD.The MOS 36-item short-form healthy survey (SF-36). I. Conceptual model and item selection. Med Care 1992; 30: 473-483.

* Ware JE jr. The SF Community - SF-36 Health survey update. http:// www.sf-36.org/tools/sf36.shtml, 2007.

* Wilson IB, Cleary PD. Linking clinical variables with health-related quality of life. A conceptual model of patient outcomes. J Am Med Assoc 1995; 273: 59-65.

* Witter DJ, Elteren P van, Käyser AF, Rossum GMJM vanOral comfort in shortened dental arches. J Oral Rehabil 1990; 17: 137-143.

* Witter DJ, Palenstein Helderman WH van, Creugers NHJ, Käyser AF. The shortened dental arch concept and its implications for oral health care. Community Dent Oral Epidemiol 1999; 27: 249-258.

* Wolfart S, Heydecke G, Luthardt RG, et alEffects of prosthetic treatment for shortened dental arches on oral health-related quality of life, self-reports of pain and jaw disability: results from the pilot-phase of a randomized multicentre trial. J Oral Rehabil 2005; 32: 815-822.

* Wöstmann B, Budtz-Jørgensen E, Jepson N, et allndications for removable partial dentures: a literature review. Int J Prosthodont 2005; 18 : 139-145.

\section{Summary}

Effects of removable partial dentures on the quality of life in peop le with shortened dental arches

In order to assess the enhanced value of removable partial dentures on the quality of life, patients at 2 university clinics were screened for the presence of complete or shortened dental arches. Those selected were assigned to 1 of 5 subgroups: 1) a shortened dental arch with all frontal teeth, 2) a shortened dental arch with one or more frontal diastemas, 3) a shortened dental arch with all frontal teeth, restored by a removable partial denture, 4) a shortened dental arch and several diastemas, restored by a removable partial denture, 5) a complete dental arch. The participants completed the Oral Health
Impact Profile (OHIP-49) and the Short Form Health Survey (SF-36). Clinical data recorded were: whether any teeth were missing and if so which, whether or not these had been replaced by a removable partial denture, and the number of occluding pairs of (pre)molars. The results revealed that a shortenend dental arch has a certain impact on the quality of life. However, the participants only experienced benefits from a removable partial denture if the denture also replaced frontal teeth.

\section{Bron}

D. B. Armellini' ${ }^{1}$ G. Heydecke², D.J. Witter ${ }^{3}$, N.H.J. Creugers ${ }^{3}$

Uit 'het Department of Restorative Dentistry, School of Dentistry, University of Maryland, ${ }^{2}$ het Department of Prosthodontics, School of Dentistry, University Medical Center Freiburg en ${ }^{3}$ de afdeling Orale Functieleer van het Universitair Medisch Centrum St Radboud in Nijmegen Datum van acceptatie: 18 december 2008

Adres: prof. dr. N.H.J. Creugers, UMC St Radboud, postbus 9.101, 6500 HB Nijmegen

n.creugers@dent.umcn.nl

\section{Verantwoording}

Dit artikel is een bewerkte vertaling van: Armellini DB, Heydecke G, Witter DJ, Creugers NHJ. Effect of removable partial dentures on oral health-related quality of life in subject with shortened dental arches: a 2 center crosssectional study. Int J Prosthodont 2008; 21: 524-530. 